\title{
KNOWLEDGE AND UTILISATION OF ANTI-SHOCK GARMENT AMONG MIDWIVES OF ADEOYO MATERNITY TEACHING HOSPITAL, IBADAN, NIGERIA
}

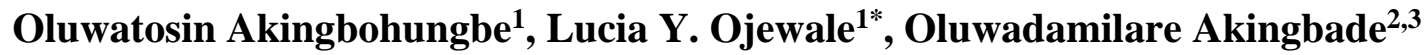 and Prisca O. Adejumo ${ }^{1}$}

${ }^{1}$ Department of Nursing, Faculty of Clinical Science, College of Medicine, University of Ibadan.

${ }^{2}$ The Nethersole School of Nursing, Faculty of Medicine, The Chinese University of Hong Kong.

${ }^{3}$ Institute of Nursing Research, Osogbo, Nigeria.

*Corresponding Email: oluwatosinsonia14@gmail.com

\section{Cite this article:}

Akingbohungbe O., Ojewale L.Y., Akingbade O., Adejumo P.O. (2021), Knowledge and Utilisation of Anti-Shock Garment Among Midwives of Adeoyo Maternity Teaching Hospital, Ibadan, Nigeria. African Journal of Health, Nursing and Midwifery 4(5), 26-37. DOI:

10.52589/AJHNM-

U47SAEMP

\section{Manuscript History}

Received: 30 June 2021

Accepted: 28 July 2021

Published: 9 Aug 2021

Copyright ()$^{2} 2020$ The Author(s). This is an Open Access article distributed under the terms of Creative Commons AttributionNonCommercial-NoDerivatives 4.0 International (CC BY-NC-ND 4.0 ), which permits anyone to share, use, reproduce and redistribute in any medium, provided the original author and source are credited.
ABSTRACT: Background and Aim: Postpartum Haemorrhage $(P P H)$ is a leading cause of maternal mortality, yet it is one of the few obstetric complications, with proven and effective interventions. NonPneumatic Anti Shock Garment (NASG) is a high-quality, simple technology and low-cost first-aid device that reverses hypovolemic shock. While evidence has shown that this simple technology is effective in reducing PPH, the level of knowledge and utilisation is unclear. This underscored the need to assess the knowledge and utilisation of the NASG as a measure of controlling postpartum haemorrhage in Adeoyo Maternity Teaching Hospital, Yemetu, Ibadan. Methods: This study adopted a descriptive cross-sectional research design and questionnaires were used to gather data from the midwives. The convenience sampling technique was used to recruit one hundred and forty-four (144) midwives into the study. Data were analysed using version 21.0 of Statistical Package for Social Sciences (SPSS) using Chi-square. Results: The findings of this study revealed that although 97.9\% of participants responded that they had seen NASG before, only about half (47.1\%) could describe what it looked like. While $96.4 \%$ claimed that they knew how to use the NASG, only $73.7 \%$ of them actually use it each time there was severe PPH. No significant association was found between knowledge and utilisation of the equipment ( $p=.298)$. Factors associated with non-usage include nonavailability, inexperience, lack of skilled personnel, and poor attitude. Conclusion: There was a good level of utilisation of the Non-Pneumatic Anti-Shock Garment for the management of postpartum haemorrhage, but only a few of the midwives were able to correctly describe it and not all were using it. Hence, refresher courses are hereby advocated to further improve NASG usage.

KEYWORDS: Postpartum Haemorrhage, Non-pneumatic Anti-shock Garment, Midwives. 


\section{INTRODUCTION}

The World Health Organization (WHO) in 2012, defined Postpartum Haemorrhage (PPH) as the loss of about 500mls of blood or more, within 24 hours after a woman has given birth. ${ }^{1}$ The condition accounts for about $25 \%$ of maternal death globally and is the most prevailing cause of maternal death in low-income countries. ${ }^{2}$ Moreover, in a multicentre study that cut across 42 tertiary hospitals in Nigeria, PPH was associated with a third of all admissions secondary to obstetric haemorrhage. ${ }^{3}$

The fatality of PPH is regarded as one of the alarming emergencies a midwife can encounter, particularly if it is a sequel to an uncomplicated delivery. The phenomenon has further led to a reduction in confidence among child-bearing women; negative attitude towards future childbearing; delay in recovery and increased risk of dying. ${ }^{4}$

Although postpartum haemorrhage is a killer, it is also one of the few obstetric complications with proven and effective interventions to reduce maternal death. An anti-shock garment also called 'Non-Pneumatic Anti-Shock Garment' (NASG) is one of such. The NASG is a lightweight, neoprene covering that resembles the bottom half of a wetsuit and is also called "life wrap". It is also described as a first-aid device in the form of a lower-body suit of articulated neoprene and velcro segments that provide lower body circumferential counter pressure which restores blood pressure to the core, thus reversing hypovolaemic shock and decreasing postpartum haemorrhage. ${ }^{6}$

NASG is defined as "a first-aid-life-sustaining-device that supports the life of a patient in haemorrhagic shock during delays in receiving appropriate healthcare services, by shunting blood from the lower body to the core organs". ${ }^{7}$ It also plays a role in sophisticated tertiary care units by keeping women stable while awaiting definitive haemorrhage therapies such as blood transfusion and surgeries. ${ }^{8}$ Similarly, in a combined study involving Nigeria and Egypt, authors affirmed that NASG was effective in reducing blood loss, emergency hysterectomy as well as $\mathrm{PPH}-$ associated morbidity and mortality. ${ }^{9}$

However, despite the introduction of this evidence-based, low-cost, and first-aid device into Nigeria in 2008, there has not been a significant reduction in maternal morbidity and mortality in Nigeria, with PPH accounting for $14 \%(40,000)$ of maternal causalities. ${ }^{10}$ Although the Nursing and Midwifery Council of Nigeria, (NMCN) in the recent past has organised workshops and training on the use of NASG for nurses and midwives within the country, nothing has been documented about the impacts of these workshops. Hence, a justification for the need to find out the level of utilisation of the NASG among midwives.

Midwives play an important role in maternity care centres in Nigeria. Evidence has shown that midwives are the first point of contact for most pregnant women and those in labour. ${ }^{11}$ A study by WHO also confirmed the important role of nurses and midwives as the organisation stated that nurses and midwives play a major role in detecting possible cases of $\mathrm{PPH}{ }^{12}$

On the other hand, assessment of knowledge of strategies used in the prevention and management of PPH among midwives in Bayelsa, south-southern Nigeria, reported that about $74 \%$ of the respondents were aware of the NASG, but only an estimated $52.5 \%$ of them affirmed to have utilised it. ${ }^{13}$ This raises the question of possible non-utilisation in other regions in the country. Therefore, the need arises to assess midwives' knowledge and level of utilisation 
of the non-pneumatic anti-shock garment, using the Adeoyo Maternity Teaching Hospital - a major maternity centre in South-west, Nigeria.

Furthermore, one of the aims of the Sustainable Development Goals (SDG), is that there should be a reduction in the global maternal mortality ratio to less than seventy per hundred thousand live births by $2030 .{ }^{14}$ To be able to achieve this, an improvement in the health of women and children is non-negotiable. Researchers' observation, as well as anecdotal evidence, suggests that many midwives do not utilise the NASG and that parturient women suffer the consequences of this. Hence, the question 'What is the self-reported level of utilisation of NASG among midwives?' It was also necessary to determine the knowledge of the midwives about NASG as this may affect the utilisation. These were the aims of this study. It is hoped that the results of the study would create awareness for policymakers at the Nursing and Midwifery Council of Nigeria (NMCN) on the need to ensure periodic training of midwives in the use of NASG.

\section{METHODS}

\section{Research Design}

The study utilised a descriptive cross-sectional design and was conducted among midwives at the Adeoyo Maternity Hospital, Ibadan. The data collection process took place in January 2018.

\section{Participants}

The inclusion criteria included midwives working at Adeoyo Maternity Teaching Hospital, Yemetu, Ibadan who consented to be part of the study. Other health professionals and those who did not give their consent to be part of the study were excluded.

\section{Sample Size Calculation}

The sample size determination was carried out using the formula: $n=\frac{N}{1+N \cdot e^{2}} \ldots$

where $\mathrm{n}$ is the minimum sample size required, $\mathrm{N}$ is the estimated population of midwives working at the Adeoyo Maternity Hospital (192), and $e$ is the degree of error tolerance (5\%). The estimated sample size was approximately 130; but with the addition of a $10 \%$ non-response rate, the sample size was finally determined to be 144 .

\section{Sampling}

A convenience sampling technique was employed for the study in selecting the one-hundred and forty-four midwives who participated.

\section{Instrument for Data Collection}

A structured self-developed questionnaire was used in obtaining information from participants. The questionnaire was divided into five sections comprising the socio-demographic details of the participants; knowledge of postpartum haemorrhage and knowledge of Non-pneumatic Anti-Shock Garment (NASG); utilisation of the NASG among the midwives and factors responsible for non-utilisation or under-utilisation of the NASG. Face and content validity was 
ensured by comparing the items with the previous similar studies and by matching them with the stated research objectives, the set research questions and the formulated research hypothesis. Before administration, copies of the instrument were reviewed, critiqued and corrected by the researchers, experts in the use of NASG alongside experts in the field of health research and medical statistics.

\section{Method of data collection}

The participants were informed of the purpose of the research and they gave their consent after which the questionnaires were administered by the first author and collected immediately. Assistance was rendered to any that needed clarification. Out of the 144 distributed questionnaires, 140 were successfully retrieved and used for the statistical analysis.

\section{Method of Data Analysis}

Analysis was done using IBM-SPSS Version 21.0. Descriptive statistics of frequency counts and percentages were used to summarise and present the results. Chi-square test was used to test the association between knowledge and utilisation of NASG. A statistical significance level of 0.05 was assigned for the statistical analysis.

\section{Ethical Consideration}

Ethical approval was obtained from the Ethics committee of the University of Ibadan University College Hospital Independent Review Board (UI-UCH IRB), with approval number $\mathrm{UI} / \mathrm{EC} / 17 / 0431$. A letter of introduction obtained from the Head of Department of Nursing was presented at the hospital to obtain the cooperation of the hospital staff. The respondents were well informed on the purpose of the study. They were informed that participation is voluntary, and they could opt out of the study if the need arose. The researchers were guided by the principles for ethical research as stated in the Declaration of Helsinki World Medical Association. ${ }^{15}$ 


\section{RESULTS}

Table 1: Socio-Demographics of the Participants

\begin{tabular}{llcc}
\hline Characteristics & & Frequency & Percentage \\
\hline \multirow{3}{*}{ Age } & 30 years \& below & 19 & 14.4 \\
& $31-40$ years & 45 & 34.1 \\
& $41-50$ years & 44 & 33.3 \\
& $51-60$ years & 24 & 18.2 \\
& Mean 40.83 \pm 9.16 & & \\
Marital Status & Single & 11 & 8.3 \\
& Married & 120 & 90.9 \\
& Widowed & 1 & 0.8 \\
Rank & NO II/NO I & 61 & 43.6 \\
& SNO & 7 & 5.0 \\
& PNO & 50 & 35.7 \\
& ACNO/CNO & 22 & 15.7 \\
Wxperience & 5 years or below & 23 & 17.3 \\
& 6 - 10 years & 36 & 27.1 \\
& 11 - 15 years & 27 & 20.3 \\
& Above 20 years & 24 & 18.0 \\
& Mean 13.50 \pm 7.78 & 23 & 17.3 \\
& & & \\
& & &
\end{tabular}

The result showed a minimum age of 24 years and a maximum age of 59 with a mean age of $41( \pm 9.16)$ years. Participants' work experience revealed a minimum of 2 years and a maximum of 30 years with a mean of $13( \pm 7.78)$ years The classification of the participants into age groups showed that above a third (34\%) of the midwives belonged to age group " $31-40$ years"; followed by $33 \%$ who belonged to age group " $41-50$ years". Marital status showed $91 \%$ were married. From details of their employment rank, about $44 \%$ were Nursing Officers while $36 \%$ were Principal Nursing Officers. Regarding their work experience at the maternity hospital, $17 \%$ had worked for 5 years; $27 \%$ had worked for " $6-10$ years"; $20 \%$ for " $11-15$ years"; $18 \%$ had worked there for " 16 - 20 years"; while 17\% had worked for over 20 years. Information on professional qualification showed that $34 \%$ had a Bachelor's degree qualification in addition to being registered Nurses and Midwives (Table 1). 
Table 2: Assessment of Midwives' Knowledge on PPH

\begin{tabular}{lcccc}
\hline & \multicolumn{2}{c}{$\begin{array}{c}\text { Right } \\
\text { Knowledge }\end{array}$} & \multicolumn{2}{c}{$\begin{array}{c}\text { Krong } \\
\text { Knowledge }\end{array}$} \\
\hline & Freq. & $\%$ & Freq. & Perc. (\%) \\
\hline $\begin{array}{l}\text { Definition of PPH as excessive } \\
\text { bleeding from the genital tract after } \\
\text { delivery }\end{array}$ & 138 & 98.6 & 2 & 1.4 \\
\hline PPH as a cause of maternal death & 139 & 99.3 & 1 & 0.7 \\
\hline $\begin{array}{l}\text { PPH is one of the few obstetric } \\
\text { complications with proven, effective } \\
\text { intervention }\end{array}$ & 139 & 99.3 & 1 & 0.7 \\
\hline $\begin{array}{l}\text { Ever heard of the Non-Pneumatic } \\
\text { Anti-Shock Garment }\end{array}$ & 140 & 100.0 & - & - \\
\hline $\begin{array}{l}\text { Ever seen the NASG } \\
\text { What NASG looks like }\end{array}$ & 137 & 97.9 & 3 & 2.1 \\
\hline $\begin{array}{l}\text { Number of parts in NASG } \\
\begin{array}{l}\text { Opinion about NASG being a new } \\
\text { technology }\end{array}\end{array}$ & 66 & 47.1 & 74 & 52.9 \\
\hline $\begin{array}{l}\text { Whether NASG works by forcing } \\
\text { blood from the lower part of the } \\
\text { body. }\end{array}$ & 134 & 95.7 & 6 & 44.3 \\
\hline $\begin{array}{l}\text { Whether garment can keep a mother } \\
\text { alive until she is treated for } \\
\text { postpartum haemorrhage }\end{array}$ & 132 & 94.3 & 8 & 5.3 \\
\hline
\end{tabular}

The entirety of the midwives (100\%) indicated that they were aware of the existence of NASG. As much as $98 \%$ reported having seen the NASG prior to the study time. Further observations from the study revealed that only about $47 \%$ of the participants truly knew what the NASG looked like. $56 \%$ of the participants had the right knowledge on the number of parts of an NASG. Up to $96 \%$ truly knew that the NASG is a new technology to reduce PPH. Up to $96 \%$ of the midwives had the knowledge that the NASG works by forcing blood from the lower part of the body to vital organs. Lastly, the knowledge about anti-shock garments being able to keep a woman alive until she is treated for PPH was common among 94\% of the midwives. The midwives sources of knowledge on postpartum haemorrhage and the NASG was from the hospital $74 \%$, while $23 \%$ indicated they learnt about them from midwifery school. (Table 2). 
Table 3: Responses on Source of Knowledge and Classification of Knowledge Test

\begin{tabular}{llcc}
\hline & & Frequency & Percentage \\
\hline & Hospital & 102 & 72.9 \\
$\begin{array}{l}\text { Sources of } \\
\text { Knowledge }\end{array}$ & School & 32 & 22.9 \\
& Seminar & 4 & 2.9 \\
& No response & 2 & 1.4 \\
$\begin{array}{l}\text { Level of Knowledge } \\
\text { on PPH \& NASG }\end{array}$ & $\begin{array}{l}\text { Fair knowledge } \\
\text { Good knowledge } \\
\text { Mean 9.57 } \pm 1.15\end{array}$ & 24 & 17.1 \\
& & 116 & 82.9 \\
\hline
\end{tabular}

To showcase the participants' composite knowledge on postpartum haemorrhage and the antishock garment, 11 items on the test of knowledge were scored, while composite scoring was carried out. Thus, one item rightly identified equates to 1 ; a total of 11 items equated to 11 . The descriptive statistics showing the composite scoring revealed that the minimum and maximum scores obtained among the participants were 7 and 11 respectively; with a mean score of $10,( \pm 1.15)$ (Table 3$)$. The knowledge score among the participants was also categorised, using the researchers" discretion; with participants with scores " 0 - 4" as "Poor Knowledge", "5 - 8" as "Fair Knowledge", and "9-11" as "Good Knowledge". The result showed that $17 \%$ had a fair knowledge level, while the remaining $83 \%$ had a good knowledge level (Table 3).

Table 4: Utilisation of Anti-Shock Garment for Postpartum Haemorrhage

\begin{tabular}{lcc}
\hline & Yes & No \\
\hline knowledge on how to use the NASG & 134 & 5 \\
& $(96.4 \%)$ & $(3.6 \%)$ \\
\hline Ever used the NASG in the management of PPH & 118 & 15 \\
\hline trained in the use of the NASG & $(84.3 \%)$ & $(5.7 \%)$ \\
\hline Presence of NASG in the health facility & 127 & 11 \\
NASG as health care protocol for PPH before referral & $(92.0 \%)$ & $(8.0 \%)$ \\
\hline use NASG every time there is severe PPH & 135 & 5 \\
\hline use it having the right technical know-how & $(96.4 \%)$ & $(3.6 \%)$ \\
\hline availability enhance usage & $97.8 \%)$ & $(2.2 \%)$ \\
\hline
\end{tabular}


On the midwives' level of utilisation of anti-shock garments as an intervention for postpartum haemorrhage, $96 \%$ indicated that they knew how to use the NASG. Up to 84\% stated they had used the NASG, at least once, before the study time. About $92 \%$ responded that they had been trained on how to use the NASG, 98\% reported that the use of NASG was part of their protocol for managing PPH before a referral is made. However, 74\% responded that they use the NASG anytime there is a case of severe PPH. All the participants, $100 \%$, answered that they would use the NASG if they knew how to use it.

Table 5: Factors associated with non-utilisation of the anti-shock garment

\begin{tabular}{|c|c|c|c|c|c|}
\hline & $\begin{array}{c}\text { Strongly } \\
\text { Agree }\end{array}$ & Agree & Disagree & $\begin{array}{l}\text { Strongly } \\
\text { Disagree }\end{array}$ & Undecided \\
\hline $\begin{array}{l}\text { Non-availability of the } \\
\text { NASG }\end{array}$ & $\begin{array}{c}35 \\
(25.7 \%)\end{array}$ & $\begin{array}{c}61 \\
(44.9 \%)\end{array}$ & $\begin{array}{c}18 \\
(13.2 \%)\end{array}$ & $\begin{array}{c}22 \\
(16.2 \%)\end{array}$ & - \\
\hline $\begin{array}{l}\text { Not aware of the garment } \\
\text { existence }\end{array}$ & $\begin{array}{c}9 \\
(6.4 \%)\end{array}$ & $\begin{array}{c}47 \\
(33.6 \%)\end{array}$ & $\begin{array}{c}45 \\
(32.1 \%)\end{array}$ & $\begin{array}{c}39 \\
(27.9 \%)\end{array}$ & - \\
\hline $\begin{array}{l}\text { Availability of other ways } \\
\text { of treating PPH. }\end{array}$ & $\begin{array}{c}31 \\
(22.6 \%)\end{array}$ & $\begin{array}{c}68 \\
(49.6 \%)\end{array}$ & $\begin{array}{c}30 \\
(21.9 \%)\end{array}$ & $\begin{array}{c}8 \\
(5.8 \%)\end{array}$ & - \\
\hline $\begin{array}{l}\text { Effective management of } \\
\text { the third stage of labour }\end{array}$ & $\begin{array}{c}73 \\
(52.1 \%)\end{array}$ & $\begin{array}{c}53 \\
(37.9 \%)\end{array}$ & $\begin{array}{c}10 \\
(7.1 \%)\end{array}$ & $\begin{array}{c}4 \\
(2.9 \%)\end{array}$ & - \\
\hline Lack of fund & $\begin{array}{c}37 \\
(26.6 \%)\end{array}$ & $\begin{array}{c}23 \\
(16.5 \%)\end{array}$ & $\begin{array}{c}43 \\
(30.9 \%)\end{array}$ & $\begin{array}{c}30 \\
(21.6 \%)\end{array}$ & $\begin{array}{c}6 \\
(4.3 \%)\end{array}$ \\
\hline $\begin{array}{l}\text { Inexperience on the part of } \\
\text { health worker }\end{array}$ & $\begin{array}{c}24 \\
(17.1 \%)\end{array}$ & $\begin{array}{c}46 \\
(32.9 \%)\end{array}$ & $\begin{array}{c}47 \\
(33.6 \%)\end{array}$ & $\begin{array}{c}23 \\
(16.4 \%)\end{array}$ & - \\
\hline Lack of skilled personnel & $\begin{array}{c}34 \\
(24.5 \%)\end{array}$ & $\begin{array}{c}34 \\
(24.5 \%)\end{array}$ & $\begin{array}{c}46 \\
(33.1 \%)\end{array}$ & $\begin{array}{c}25 \\
(18.0 \%)\end{array}$ & - \\
\hline $\begin{array}{l}\text { The garment is not } \\
\text { convenient }\end{array}$ & $\begin{array}{c}10 \\
(7.1 \%)\end{array}$ & $\begin{array}{c}22 \\
(15.7 \%)\end{array}$ & $\begin{array}{c}73 \\
(52.1 \%)\end{array}$ & $\begin{array}{c}35 \\
(25.0 \%)\end{array}$ & - \\
\hline $\begin{array}{l}\text { Poor attitude of health } \\
\text { workers towards the use of } \\
\text { NASG }\end{array}$ & $\begin{array}{c}17 \\
(12.1 \%)\end{array}$ & $\begin{array}{c}34 \\
(24.3 \%)\end{array}$ & $\begin{array}{c}53 \\
(37.9 \%)\end{array}$ & $\begin{array}{c}36 \\
(25.7 \%)\end{array}$ & - \\
\hline
\end{tabular}

Not more than $40 \%$ generally agreed that lack of awareness of the garment existence is a major factor responsible for the non-utilisation of the NASG. 71\% generally agreed to the assertion that the non-usage of NASG among midwives is caused by the non-availability of the instrument. Up to $73 \%$ responded that the availability of other ways of treating postpartum haemorrhage is also a factor responsible for the non-utilisation of the NASG. Up to $90 \%$ cumulatively agreed that effective management of the third stage of labour has been a major factor responsible for the non-utilisation of the NASG. Not more than $43 \%$ of the midwives agreed to the assertion that the non-utilisation of the NASG can be attributed to a lack of funds. Up to $50 \%$ of them agreed that inexperience on the part of the health workers can be a factor responsible for the non-utilisation of the NASG. 49\% agreed to the assertion that lack of skilled personnel is also a factor responsible for the non-utilisation of the anti-shock garment. $23 \%$ 
attributed the non-utilisation of the NASG to the inconvenience caused by the garment. Only about $36 \%$ responded that the non-utilisation of the NASG can be faulted to the poor attitude of the health workers due to the use of it.

Table 6: Association between knowledge and utilisation of NASG among midwives on postpartum haemorrhage

\begin{tabular}{llllll}
\hline & & \multicolumn{2}{l}{ Knowledge } & \multirow{2}{*}{$\chi^{2}$} & P-value \\
\cline { 3 - 4 } & & Yes & No & 1.082 & 0.298 \\
\hline $\begin{array}{llll}\text { utilisation } \\
\text { of NASG }\end{array}$ & Fair & 24 & 0 & & \\
Total & & 110 & 5 & & \\
\hline
\end{tabular}

Table 6 shows that there is no significant association between the knowledge of the respondents and their utilisation of NASG, with a p-value $>0.05\left(0.298, \chi^{2}=1.082\right)$. Therefore, the researchers fail to reject the null hypothesis.

\section{DISCUSSION}

The majority of respondents were married females while the average age estimate among them was approximately 41 years. Most of the respondents were diploma (RN/RM) with only a few having university degrees. This corresponds to the findings of the study conducted by earlier researchers in this domain. ${ }^{16}$ The number of years that respondents had spent in practice showed an average estimate of 13 years thus, implying that the majority of the respondents were employed not quite long after their licensing into the profession and they are expected to be aware of new technologies and strategies in the prevention of PPH.

Knowledge of the NASG was high among the respondents. This is similar to the submission of a past study that assessed midwives' knowledge and utilisation of NASG in Bayelsa. ${ }^{17}$ Although the participants in our study had good knowledge about the mechanism of action and use of NASG, there are still gaps in their knowledge as their knowledge on the description of NASG was poor, unlike a previous study ${ }^{17}$ where the midwives demonstrated good knowledge on description, mechanism of action, and uses of NASG. The inability of the midwives in our study to describe the parts of the NASG calls to question if they were regularly utilising the NASG as regular usage should make them familiar with the parts of the NASG. Although 92\% reported they have been trained on the usage of NASG, there are still gaps in their knowledge even as 31\% reported that they were not using it because they do not know about it. This highlights the need for refresher courses.

On the level of utilisation of NASG, this study revealed that although $96 \%$ of the respondents reported they knew how to use the NASG, only $84 \%$ has used the NASG in the management of PPH at least once. Not more than 74\% responded that they use the NASG anytime there is a case of severe postpartum haemorrhage. Although the respondents confirmed the presence of the NASG in their facility, more than two-tenths of the respondents reported non-usage of the 
equipment anytime there is PPH, which suggests underutilisation of the equipment. While this study found that $84 \%$ of the respondents had used NASG at least once, a study among midwives in University College Hospital, Ibadan, South-West Nigeria found that majority of the respondents had good knowledge of NASG but $65 \%$ had never applied it on clients. ${ }^{18}$ This highlights a theory-practice gap among midwives concerning NASG usage. This was supported by our study as we found no significant association between knowledge and utilisation of NASG $(p=.298)$. This was also in tandem with the finding of a study on assessment of the utilisation of NASG in Ondo State, South-West Nigeria, where only $14.1 \%$ of the midwives utilise the garment when the need arises. ${ }^{17}$

Understanding the factors responsible for the non-usage of NASG will give insight into probable interventions that might improve utilisation. In our study, we found that $71 \%$ agreed that the non-usage of NASG is due to its non-availability. There is a need to ensure the adequate provision of NASG in maternity units. Furthermore, half of the respondents affirmed that inexperience on the part of the midwife is a factor responsible for non-usage. This was in consonance with the finding of research conducted among health workers in maternity care in Northern Ethiopian hospitals where inexperience was significantly associated with the nonutilisation of NASG. ${ }^{19}$ Similarly, close to half of the respondents submitted that lack of skilled personnel is a factor responsible for non-usage. This suggests that midwives should build more skills in the use of NASG. Only about $36 \%$ agreed that the non-utilisation of the NASG can be due to the poor attitude of the health workers. However, in a study among health workers in maternity care in Southwest Ethiopia, having a positive attitude was found as a significant factor associated with the utilisation of NASG ${ }^{20}$ Organising seminars on the usage of NASG is hereby suggested as this might improve their attitude towards its usage.

\section{Implication for Practice}

As gaps were found in the knowledge of midwives on NASG in this study, this calls for refresher courses for midwives on the usage of NASG. It is hoped that this will also improve the attitude of midwives towards the equipment. In a bid to improve utilisation of the equipment, a monitoring system is hereby suggested as this might help to improve utilisation. Similarly, as a large percentage of the respondents reported lack of the equipment as a factor associated with non-usage, the hospital authority should ensure that all maternity units have access to the equipment. Policymakers like the Nursing and Midwifery Council of Nigeria should ensure that continuing education programs on the use of NASG are effective.

\section{Strength and Limitation}

This study has added to the body of evidence available on the knowledge and utilisation of NASG among midwives in Ibadan. Factors associated with the non-utilisation of the equipment with possible suggestions were also identified. However, this study has some limitations. As the study was based on self-report, there is the possibility of social desirability bias as the respondents might under-report poor utilisation. Similarly, as the study was conducted in just one hospital, this might not provide a clear picture of what is obtainable among all midwives in Ibadan or Oyo State. Hence, these limitations should be considered when interpreting the findings. This calls for more studies with a larger sample size to provide a broader picture. 


\section{CONCLUSION}

The study shows that midwives have a good knowledge of NASG, although some gaps were identified. the utilisation of NASG was above average although more than two-tenths reported non-utilisation during PPH. Factors associated with non-usage were also identified which include non-availability, inexperience, lack of skills and poor attitude. As no significant association was found between knowledge and utilisation, this calls for more training to build the skills of midwives in the usage of NASG, thus bridging the theory-practice gap.

\section{REFERENCES}

[1]. World Health Organization. Recommendations on prevention and treatment of postpartum

haemorrhage.https://apps.who.int/iris/bitstream/handle/10665/75411/9789241548502_e ng.pdf;jsessionid=9AEBC5E95E1F78DD751049EB59C178DA? sequence $=12012$.

Published 2012. Accessed July 23, 2018.

[2]. Say L, Chou D, Gemmill A, Tunçalp Ö, Moller AB, Daniels J, Gülmezoglu AM, Temmerman M, Alkema L. Global causes of maternal death: a WHO systematic analysis. Lancet Glob Health. 2014;2(6):e323-33. DOI: 10.1016/S2214109X(14)70227-X.

[3]. Sotunsa JO, Adeniyi AA, Imaralu JO, Fawole B, Adegbola O, Aimakhu CO, Adeyemi AS, Hunyinbo K, Dada OA, Adetoro OO, Oladapo OT. Maternal near-miss and death among women with postpartum haemorrhage: a secondary analysis of the Nigeria Nearmiss and Maternal Death Survey. BJOG 2019; 126 (S3): 19-25.

[4]. Ajenifuja K.O, Adepiti C.A, Ogunniyi S.O Postpartum haemorrhage in a teaching hospital in Nigeria: a 5-year experience. Afr Health Sci 2010 Mar;10(1):71-4.

[5]. Christopher B, Louis G, Andre B. Mahantesh Karoshi.A textbook of Postpartum Haemorrhage. $1^{\text {st }}$ ed, Sapiens publishing, Duncow, KirkmaticeDumfriesshire, DGHITA; 2006:65

[6]. The International Statistical Classification of Disease and Related health problems, tenth revision, Australian Modification (ICD-10-AM) (2002)

[7]. The American College of Obstetrics and Gynecology: https://www.acog.org/ Accessed June 29, 2018.

[8]. Sobieszczyk S, Breborowics C.H. 2004. Management recommendations for postpartum haemorrhage; Arch Perinatal med; 10;01

[9]. Miller S, Turan JM, Ojengbede O, Fathalla M, Morhason-Bello IO, Youssif MM, Galandanci $\mathrm{H}$ et al (2006). The Pilot study of the non-pneumatic anti-shock garment (NASG) in women with severe obstetric haemorrhage: Combined results from Egypt and Nigeria. International Journal of Gynecology and Obstetrics:94 (Supplement 3), S43-S44

[10]. United Nation Population Fund, World Health Organisation, United Nation Children Fund and World Bank, 2012

[11]. Onasoga Olayinka A, Awhanaa Akpomeyoma T, Amiegheme Felicia E. Assessment of knowledge of strategies used in the prevention and management of postpartum haemorrhage by midwives in Bayelsa Nigeria. Arch Appl Sci Res. 2012;4(1):447-53. 
[12]. WHO. (2011). State of the World's Midwifery Report 2011: Delivering Health. Midwifery Report. Retrieved from: http://www.who.int/pmnch/media/membernews/2011/20110620_sowmr/en/index.html

[13]. Onasoga Olayinka A, Awhanaa Akpomeyoma T, Amiegheme Felicia E. Assessment of knowledge of strategies used in the prevention and management of postpartum haemorrhage by midwives in Bayelsa Nigeria. Arch Appl Sci Res. 2012;4(1):447-53.

[14]. Abdul-Kadir R, McLintock C, Ducloy AS, El-Refaey H, England A, Federici AB, et al. Evaluation and management of postpartum haemorrhage: consensus from an international expert panel. Transfusion. 2014;54(7):1756-68

[15]. World Medical Association (2013). World Medical Association Declaration of Helsinki: ethical principles for medical research involving human subjects. JAMA, 310(20), 2191-2194. https://doi.org/10.1001/jama.2013.281053

[16]. Ogbeye GB, Ohaeri BM, Olatubi MI. Midwives knowledge and attitude towards the use of anti-shock garments in the control of postpartum haemorrhage in selected hospitals in Ondo state. Int J Health Sci. Res. 2015; 5(9):389-395

[17]. Onasoga OA, Duke E, Danide IU, Jack-Ide IO. Midwives' knowledge and utilisation of non-pneumatic anti-shock garments in reducing the complication of postpartum haemorrhage in selected health care facilities in Bayelsa state Nigeria. Int J Reprod Contracept Obstet Gynecol 2015; 4:977-81.

[18]. Kolade O.A, Tijani W.A, Oladeji, M.O, Ajibade B.L; Midwives' Knowledge and utilisation of Anti-Shock Garment in Prevention of Postpartum Haemorrhage Shock at the University College Hospital, Ibadan Nigeria. Int J Caring Sci 2017; 10,1:327

[19]. Desta AA, Berhane M, Woldearegay TW. utilisation Rate and Factors Associated with Non-utilisation of Non-Pneumatic Anti-Shock Garment in the Management of Obstetric Hemorrhage in Public Health Care Facilities of Northern Ethiopia: A Cross-Sectional Study. Int J Women's Health. 2020;12:943-951 https://doi.org/10.2147/IJWH.S266534

[20]. Bekele, G., Terefe, G., Sinaga, M. et al. utilisation of non-pneumatic anti-shock garment and associated factors for postpartum haemorrhage management among health care professionals in public hospitals of Jimma zone, south-West Ethiopia, 2019. Reprod Health 17, 37 (2020). https://doi.org/10.1186/s12978-020-0891-6 